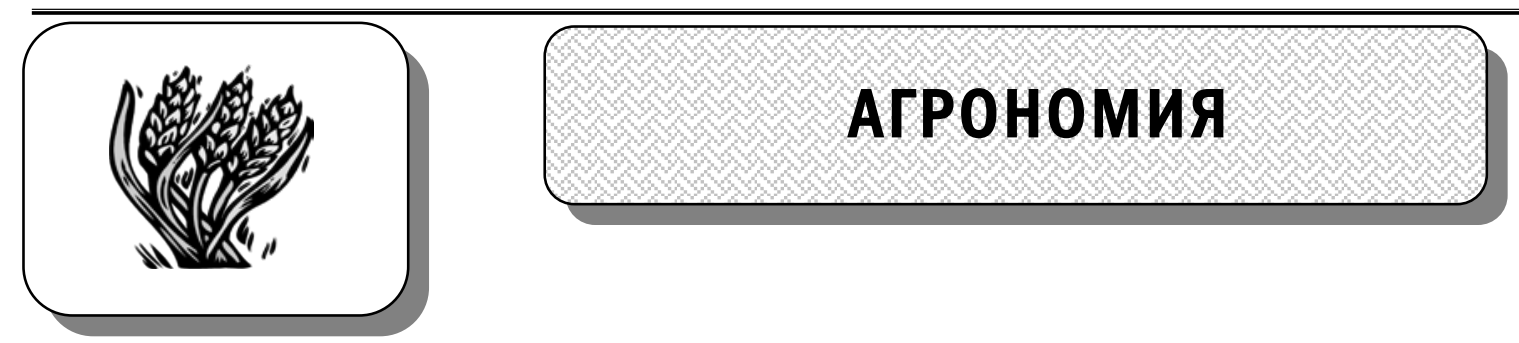

УДК 633.2 .031

В.В. Осипова, Л.Я. Конощук

DOI: 10.36718/1819-4036-2019-11-3-8

\title{
ПРОДУКТИВНОЕ ДОЛГОЛЕТИЕ МНОГОЛЕТНИХ ЗЛАКОВЫХ ТРАВ В УСЛОВИЯХ МЕРЗЛОТНЫХ ПОЧВ НЮРБИНСКОГО УЛУСА РЕСПУБЛИКИ САХА (ЯКУТИЯ)
}

\author{
V.V. Osipova, L.Ya. Konoshchuk
}

\section{PRODUCTIVE LONGEVITY OF PERENNIAL CEREAL GRASSES UNDER CONDITIONS OF FROZEN SOILS OF NURBINSK ULUS OF THE REPUBLIC OF SAKHA (YAKUTIA)}

Ocunoва B.B. - д-р с.-х. наук, доц. каф. агрономии Октемского филлиала Якутской государственной сельскохозяйственной академии, Республика Саха (Якутия), Хангаласский р-н, с. Октемцы.

E-mail: luzerna_2008@mail.ru

Конощук Л.Я. - ассист. каф. агрономии Октемского филиала Якутской государственной сельскохозяйственной академии, Республика Саха (Якутия), Хангаласский р-н, с. Октемцы.

E-mail: luzerna_2008@mail.ru

Цель исследования - изучение зависимости долголетней кормовой и семенной продуктивности многолетних трав от сортовых особенностей на мерзлотных почвах Привилюйской зоны. Задачи исследования: определить долголетнюю кормовую и семенную продуктивность сортов костреца безостого, овсяницы красной, ломкоколосника ситникового; изучить зимостойкость сортов костреца безостого, овсяницы красной, ломкоколосника ситникового. Объекты исследования - сорта трех видов многолетних трав: костреца безостого (Камалинский 14, Аммачаан, Хаптагайский), овсяницы красной (Мюрюнская, Энсиэли) и ломкоколосника ситникового (Боотур, Иэттээн, Манчаары). Посев опытов был проведен 15 июня 2009 г. Агрохимические показатели почвы пахотного слоя участка: $\mathrm{pH}-7,8-7,9$; содержание N - 1,04-3,46; PO - 13,1-13,7; KO -
Osipova V.V. - Dr. Agr. Sci., Assoc. Prof., Chair of Agronomy, Oktemsky Branch, Yakut State Agricultural Academy, Republic of Sakha (Yakutia), Hangalass District, V. Oktemtsa.

E-mail: luzerna_2008@mail.ru

Konoshchuk L.Ya. - Asst, Chair of Agronomy, Oktemsky Branch, Yakut State Agricultural Academy, Republic of Sakha (Yakutia), Hangalass District, V. Oktemtsa.

E-mail: luzerna_2008@mail.ru

13,8-31,0 м2/100 2; содержание гумуса 2,6-3,4\%. Предшественник - чистый пар. Учеты и наблюдения по решению задач исследования проводились в соответствии с общепринятыми методиками. Опьты закладывались в четырехкратной повторности при рендомизированном размещении вариантов с площадью делянок $25 \mathrm{M}^{2}$. В опытах на корм сорта высевались сплошным рядовым способом с нормой высева семян: костреца безостого - 20,0 ке/га; у овсяницы красной - 14,0; ломкоколосника ситникового - 16,0 ке/га. В опытах на семена ширина междурядий составляла 45 см, норма высева семян у костреца безостого - 10,0 кг/га; у овсяницы красной 7,0; ломкоколосника ситникового - 8,0 ке/га. Выявлено, что сорта изученных видов многолетних трав отлично перезимовывают в суровых условиях мерзлотных почв Нюрбинского 
района Якутии и сохраняют высокопродуктивные травостои. Сорт Хаптагайский костреца безостого дает высокие урожаи до 6 лет (2,22 m/2а сена и 2,67 и/га семян), сорт Мюрюнская овсяницы красной - в течение 5 лет (1,78 m/2а сена и 1,24 и/га семян), сорт ломкоколосника ситникового Боотур - в течение всех 8 лет наблюдений $(1,46 \mathrm{~m} / 2 а$ сена и 1,01 и/га семян).

Ключевые слова: многолетние травы, мерзлотные почвы, долголетие, продуктивность, сено, семена.

The research objective was studying the dependence of long term fodder and seed efficiency of perennial grasses on variety features on permafrost soils of Privilyuysk zone. The research problems were to define long term fodder and seed efficiency of the varieties of Bromus inermis, Festuca rubra, Psathyrostachys juncea; to study winter hardiness of varieties of Bromus inermis, Festuca rubra, Psathyrostachys juncea. The objects of the research were the varieties of three species of perennial grasses: Bromus inermis (Kamalinsky 14, Ammachaan, Haptagaysky), Festuca rubra (Myuryunskaya, Ensieli) and Psathyrostachys juncea (Bootur, letteen, Manchaara). The seeding of experimental grasses was carried out on June 15, 2009. Agrochemical indicators of the soil of an arable layer of the plot were $\mathrm{pH}-7.8-7.9$; $\mathrm{N}$ content - 1.04-3.46; $\mathrm{PO}$ - 13.1-13.7; KO - 13.8-31.0 mg / 100; the maintenance of humus - 2.6-3.4\%. The predecessor was bare fallow. The accounts and supervision of the solution of the research problems were made according to standard techniques. The experiments were put in quadruple frequency at randomized placement of options with an area of allotments of $25 \mathrm{~m}^{2}$. In the experiments on forage the varieties were sown in continuous row way with the norm of seeding: Bromus inermis - 20.0 kg/hectare; Festuca rubra - 14.0; Psathyrostachys juncea $16.0 \mathrm{~kg} / \mathrm{hectare}$. In the experiments on seeds the width of row-spacing made $45 \mathrm{~cm}$, the norm of seeds seeding in Bromus inermis - $10.0 \mathrm{~kg} / \mathrm{hectare}$; in Festuca rubra - 7.0; Psathyrostachys juncea $8.0 \mathrm{~kg} / \mathrm{hectare}$. It was revealed that the varieties of studied species of perennial grasses had wintered perfectly in severe conditions of permafrost soils of Nyurbinsk Region of Yakutia and keep highly productive herbages. Haptagaysky cultivar of Bromus inermis yields big crops up to 6 years (2.22 thectare of hay and 2.67 c/hectare of seeds), the variety Myuryunskaya of Festuca rubra - within 5 years (1.78 t/hectare of hay and 1.24 c/hectare of seeds), Psathyrostachys juncea variety Bootur - within all 8 years of supervision (1.46 thectare of hay and $1.01 \mathrm{c} /$ hectare of seeds)

Keywords: perennial grasses, permafrost soils, longevity, productivity, hay, seeds.

Введение. Условия перезимовки луговых многолетних трав в Якутии служат эталоном предельной жесткости перезимовки трав в Северном полушарии планеты. Предпосылками этого являются рекордно низкие температуры воздуха зимой (минус $60-70^{\circ} \mathrm{C}$ ), а также то обстоятельство, что на большей площади лугов утепляющий эффект снежного покрова сводится на нет активной тебеневкой табунов якутских лошадей, которые, добывая корм, разрушают утепляющий почву снежный покров, а подчас вообще оголяют значительную поверхность лугов от снежного покрова [1]. В итоге температура почвы на глубине узлов кущения луговых растений в сильные морозы опускается до минус $35-40{ }^{\circ} \mathrm{C}$ ниже нуля [5]. В таких случаях практически все сорта луговых растений, созданные селекционерами в других странах и европейской части России, вымерзают. Исключение составляют единичные сибирские сорта. Именно это обстоятельство на протяжении более полувека препятствовало успешному развитию травосеяния в Якутии [2].

Травосеяние получило признание производства лишь тогда, когда были изучены экологобиологические азы травосеяния и разработаны технологические основы возделывания трав при коренном улучшении важнейших типов деградированных лугов республики, а самое главное - после того, как было организовано в Якутии собственное семеноводство трав на промышленной основе, которое распадом больших сельскохозяйственных предприятий прекратила свою деятельность [3].

Сегодня вполне очевидно, что главная причина низких и неустойчивых показателей развития животноводства и коневодства республики слабая и нестабильная по годам кормовая база.

Важной задачей кормопроизводства является расширение видового и сортового состава 
кормовых растений. Нужны все новые, приспособленные к разнообразным природноклиматическим условиям районов республики виды и сорта многолетних трав. Только обогащение ассортимента используемых многолетних трав районированием всех новых селекционных сортов, а также за счет окультуривания и внедрения урожайных, устойчивых к болезням и вредителям, ценных по кормовым достоинствам, хорошо приспособленных к суровым условиям местных дикорастущих видов позволит увеличить урожайность и качество кормовой массы, повысить продуктивное долголетие сеяных сенокосов и пастбищ, расширит районы применения интенсивных технологий лугового кормопроизводства [6].

Нюрбинский район с давних времен является сельскохозяйственным районом, однако, как и во всей республике, развитие животноводства здесь ограничено хронически испытываемым недостатком кормов. Одна из причин такого положения - это очень длинный стойловый период, продолжающийся в течение восьми месяцев. Заготовить достаточное количество корма за короткое якутское лето - задача трудная, но вполне разрешимая [4].

В настоящее время около 80-90 \% кормов для животноводства республики дают малопродуктивные естественные угодья; попытки их улучшения пока не дали ощутимых результатов [6].

Основное условие увеличения производства продуктов животноводства - создание кормовой базы. Она должна не только полностью обеспечивать, но и превышать потребности животноводства по объему и разнообразию. Только в этом случае можно будет обеспечить быстрый рост поголовья скота и его продуктивности. Сеяные многолетние бобовые и злаковые травы дают ценный высокопитательный корм, охотно поедаемый домашними животными.

Для решения проблем, связанных с повышением урожайности сенокосов и пастбищ, обязательно надо возобновлять организацию семеноводства многолетних трав, которая обеспечивала бы элитными районированными семенами сортов многолетних трав.

Цель исследования: изучение зависимости долголетней кормовой и семенной продуктивности многолетних трав от сортовых особен- ностей на мерзлотных почвах Привилюйской зоны.

Задачи исследования:

- определить долголетнюю кормовую и семенную продуктивность сортов костреца безостого, овсяницы красной, ломкоколосника ситникового;

- изучить зимостойкость сортов костреца безостого, овсяницы красной, ломкоколосника ситникового.

Объекты и методы исследования. Объектами исследования являлись три вида многолетних трав: кострец безостый, овсяница красная и ломкоколосник ситниковый. У костреца безостого исследовались сорта Камалинский 14, Аммачаан, Хаптагайский; у овсяницы красной - Мюрюнская и Энсиэли; ломкоколосника ситникового сорта Боотур, Иэттээн и Манчаары.

Климат района резко континентальный с низкими температурами воздуха зимой (до минус $\left.62^{\circ} \mathrm{C}\right)$ и высокими летом (до $\left.+40{ }^{\circ} \mathrm{C}\right)$. Слой подстилаемой вечной мерзлоты - до 600 м, глубина сезонного протаивания - 170-180 см. Тип почвы и механический состав - пойменная (аллювиальная) суглинистая. Агрохимические показатели почвы пахотного слоя участка: $\mathrm{pH}$ - 7,8-7,9; содержание N - 1,04-3,46 мг/100 г; PO - 13,1-13,7; КО - 13,8-31,0; содержание гумуса - 2,6-3,4 \%.

Предшественник - чистый пар.

Учеты и наблюдения по решению задач исследования проводились в соответствии с общепринятыми методиками.

Опыты закладывались в четырехкратной повторности при рендомизированном размещении вариантов с площадью делянок $25 \mathrm{~m}^{2}$, ширина междурядий в опыте на корм - 15 cм, на семена - 45 см.

Посев опытов был проведен 15 июня 2009 г. Семена трав высеяли во влажную почву с нормой высева в опыте на корм костреца безостого - 20,0 кг/га; овсяницы красной - 14,0; ломкоколосника ситникового - 16,0 кг/га. Норма высева в опыте на семена костреца безостого 10,0 кг/га; овсяницы красной - 7,0; ломкоколосника ситникового - 8,0 кг/га.

Семена убирали комбайном «Сампо-130» в фазу хозяйственной спелости семян.

Результаты исследования. Проанализировав результаты многолетних данных по кормовой продуктивности сортов трав, можно утверждать, что сорта костреца безостого Камалинс- 
Вестник КрасТАУ. 2019. № 11

кий 14 и Аммачан за 7 лет использования дают стабильные урожаи сена в течение 4 лет, с пятого года кормовая урожайность начинает снижаться, у сорта Хаптагайский снижение урожайности начинается с шестого года пользования (табл. 1). У овсяницы красной сорта Мюрюнская и Энсиэли обеспечивают стабильные урожаи сена в течение 5 лет. Все изученные сорта ломкоколосника ситникового не снижают кормовую урожайность в течение всех 8 лет наблюдений.

Таблица 1

Кормовая продуктивность сортов многолетних трав (абсолютно сухое вещество), т/га (за период 2010-2016 гг.)

\begin{tabular}{|c|c|c|c|c|c|c|c|c|c|}
\hline \multirow[b]{2}{*}{ Культура, сорт } & \multicolumn{7}{|c|}{ Год жизни } & \multirow{2}{*}{$\begin{array}{c}\text { Сред- } \\
\text { нее } \\
\text { за все } \\
\text { годы }\end{array}$} & \multirow{2}{*}{$\begin{array}{c}\text { Откло- } \\
\text { нение } \\
\text { от St }\end{array}$} \\
\hline & 2-й & 3-й & $4-\breve{n}$ & 5-й & 6-й & 7-й & 8-й & & \\
\hline \multicolumn{10}{|c|}{ Кострец безостый } \\
\hline Камалинский 14-St & 1,68 & 2,06 & 2,20 & 2,87 & 1,69 & 1,93 & 1,40 & 1,97 & St \\
\hline Аммачан & 1,63 & 1,96 & 2,30 & 2,75 & 1,84 & 1,90 & 1,44 & 1,97 & 0 \\
\hline Хаптагайский & 2,02 & 2,36 & 2,78 & 2,63 & 2,40 & 1,80 & 1,56 & 2,22 & $+0,29$ \\
\hline $\mathrm{HCP}_{05}$ & 0,18 & 0,12 & 0,11 & 0,11 & 0,16 & 0,10 & 0,09 & 0,15 & \\
\hline \multicolumn{10}{|c|}{ Овсяница красная } \\
\hline Мюрюнская - St & 1,83 & 1,95 & 1,96 & 1,89 & 1,91 & 1,58 & 1,32 & 1,78 & St \\
\hline Энсиэли & 1,57 & 1,61 & 1,84 & 1,80 & 1,58 & 1,36 & 1,10 & 1,55 & $-0,23$ \\
\hline $\mathrm{HCP}_{05}$ & 0,17 & 0,14 & 0,17 & 0,15 & 0,32 & 0,30 & 0,15 & 0,16 & - \\
\hline \multicolumn{10}{|c|}{ Ломкоколосник ситниковый } \\
\hline Боотур - St & 1,17 & 1,34 & 1,50 & 1,44 & 1,74 & 1,52 & 1,50 & 1,46 & St \\
\hline ИэттэЭн & 1,10 & 1,17 & 1,28 & 1,24 & 1,22 & 1,10 & 0,93 & 1,15 & $-0,31$ \\
\hline Манчаары & 1,12 & 1,12 & 1,37 & 1,32 & 1,48 & 1,45 & 1,38 & 1,32 & $-0,14$ \\
\hline $\mathrm{HCP}_{05}$ & 0,09 & 0,10 & 0,11 & 0,17 & 0,16 & 0,30 & 0,41 & 0,12 & \\
\hline
\end{tabular}

При этом наиболее урожайными по выходу кормовой массы из изученных видов трав явились сорта: костреца безостого - Хаптагайский (2,22 т/га), овсяницы - Мюрюнская (1,78 т/га), ломколосника ситникового - Боотур (1,46 т/га).

Семенная продуктивность изученных видов трав была по всем годам не высокая, но стабильная (табл. 2). Урожайность семян всех изученных сортов костреца безостого повышалась с первого по пятый год жизни с 1,46-1,50 до 2,56-3,29 ц/га. Наибольшая урожайность семян в среднем за 5 лет использования травостоя отмечена у сорта Хаптагайский - 2,67 ц/га, что на 0,2 ц выше, чем у стандарта Камалинский 14.

\section{Семенная продуктивность сортов многолетних трав, ц/га} (за период 2010-2014 гг.)

\begin{tabular}{|c|c|c|c|c|c|c|c|}
\hline \multirow{2}{*}{ Культура, сорт } & \multicolumn{5}{|c|}{ Год жизни } & \multirow{2}{*}{$\begin{array}{c}\text { Среднее } \\
\text { за все } \\
\text { годы }\end{array}$} & \multirow{2}{*}{$\begin{array}{l}\text { Отклоне- } \\
\text { ние от } \mathrm{St}\end{array}$} \\
\hline & $2-\breve{n}$ & 3-й & 4-й & $5-\breve{и}$ & 6-й & & \\
\hline 1 & 2 & 3 & 4 & 5 & 6 & 7 & 8 \\
\hline \multicolumn{8}{|c|}{ Кострец безостый } \\
\hline Камалинский 14 - St & 1,50 & 2,85 & 3,02 & 3,14 & 1,87 & 2,48 & St \\
\hline Аммачан & 1,32 & 2,11 & 2,56 & 2,70 & 1,50 & 2,04 & $-0,44$ \\
\hline Хаптагайский & 1,46 & 3,04 & 3,29 & 3,41 & 2,18 & 2,68 & $+0,20$ \\
\hline
\end{tabular}




\begin{tabular}{|l|c|c|c|c|c|c|c|}
\hline \multicolumn{1}{|c|}{1} & 2 & 3 & 4 & 5 & 6 & 7 & Окончание табл. 2 \\
\hline HСР $_{05}$ & 0,11 & 0,15 & 0,20 & 0,18 & 0,20 & 0,14 & - \\
\hline \multicolumn{7}{|c|}{ Овсяница красная } \\
\hline Мюрюнская - St & 0,34 & 1,32 & 1,04 & 2,17 & 1,34 & 1,24 & St \\
\hline Энсиэли & 0,44 & 0,80 & 0,74 & 2,54 & 1,14 & 1,13 & $-0,11$ \\
\hline НСР $_{05}$ & 0,08 & 0,20 & 0,52 & 0,18 & 0,11 & 0,09 & - \\
\hline \multicolumn{7}{|c|}{ Ломкоколосник ситниковый } \\
\hline Боотур - St & 0,79 & 0,79 & 1,23 & 0,57 & 1,46 & 1,01 & St \\
\hline Иэттээн & 0,39 & 0,40 & 0,69 & 0,74 & 1,66 & 0,78 & $-0,23$ \\
\hline Манчаары & 0,35 & 0,30 & 1,09 & 0,59 & 0,29 & 0,52 & $-0,49$ \\
\hline НСР 05 & 0,08 & 0,08 & 0,11 & 0,10 & 0,15 & 0,19 & - \\
\hline
\end{tabular}

В течение 5 лет использования у сортов овсяницы красной наблюдалось повышение семенной продуктивности с третьего года жизни травостоя до пятого (0,34-2,54 ц/га) и начало снижения урожайности с шестого года. Наиболее высокий семян отмечен у стандартного сорта Мюрюнская (1,24 ц/га).

Семенная продуктивность сортов ломкоколосника ситникового не высокая, но стабильная по годам использования в пределах от 0,35 до 1,66 ц/га. Средняя за все годы урожайность семян сортов Иэттээн и Манчаары ниже, чем у стандартного сорта Боотур на 0,23 и 0,49 ц/га соответственно.

В течение 7 лет изучения сортов многолетних трав не было выявлено гибели растений от вымерзания. Во все годы исследования все сорта костреца безостого, овсяницы красной и ломкоколосника ситникового показали исключительно высокую зимостойкость.

Выводы. Установлено, что в условиях мерзлотных таежных палевых почв Нюрбинского района Республики Саха (Якутия) наиболее долголетнее продуктивное использование травостоев на корм обеспечивает сорт костреца безостого Хаптагайский (6 лет), сорта Камалинский 14 и Аммачан показали стабильные урожаи сена в течение 4 лет. Сорта овсяницы красной Мюрюнская и Энсиэли позволяют получать стабильные урожаи сена в течение 5 лет использования посевов. Сорта ломкоколосника ситникового Боотур, Иэттээн, Манчаары не снижают кормовую урожайность в течение всех 8 лет наблюдений. Отмечены наиболее урожайные по выходу кормовой массы сорта костреца безостого Хаптагайский $(2,22$ т/га), овсяницы красной
Мюрюнская (1,78 т/га), ломкоколосника ситникового Боотур (1,46 т/га).

Сорта костреца безостого, овсяницы красной и ломкоколосника ситникового в течение 6 лет жизни травостоев показали не высокую, но стабильную семенную продуктивность. Наибольшая урожайность семян в среднем за 5 лет использования травостоя отмечена у сорта Хаптагайский костреца безостого - 2,68 ц/га, сорта Мюрюнская овсяницы красной - 1,24 ц/га и сорта Боотур ломкоколосника ситникового 1,01 ц/га.

В жестких условиях перезимовки на мерзлотных таежных палевых почвах Нюрбинского района Якутии все испытанные сорта костреца безостого, овсяницы красной, ломкоколосника ситникового отлично перезимовывают.

\section{Литература}

1. Денисов Г.В., Стрельцова В.С., Борисов В.3. Агрометеорологические факторы в формировании продуктивности сеяных лугов в Якутии // Сельскохозяйственная биология. - 1982. - № 4. - С. 103-115.

2. Денисов Г.В. Многолетние травы на вечной мерзлоте (Крайний Север) // Сельское хозяйство России. - 1971. - № 9. - С. 31.

3. Денисов Г.В. Эколого-биологические основы возделывания многолетних трав в зоне вечной мерзлоты: автореф. дис. ... д-ра биол. наук / Центр. сиб. ботан. сад, Сиб. отд-ние. - Новосибирск, 1987. - 32 с.

4. Денисов Г.В., Стрельщова В.С. Экология и эволюция сеяных лугов в криолитозоне. Новосибирск: Изд-во РАН, 2005. - 240 с. 
5. Еловская Л.Г. Почвы земледельческих районов Якутии и пути повышения их плодородия. - Якутск, 1964. - 76 с.

6. Павлов Н.Е. Семеноводство и сортоведение многолетних трав в Якутии. - Якутск: Туймаада, 2012. - 111 с.

\section{Literatura}

1. Denisov G.V., Strel'cova V.S., Borisov V.Z. Agrometeorologicheskie faktory $\mathrm{V}$ formirovanii produktivnosti seyanyh lugov $\mathrm{V}$ Yakutii II Sel'skohozyajstvennaya biologiya. - 1982. - № 4 S. 103-115.

2. Denisov G.V. Mnogoletnie travy na vechnoj merzlote (Krajnij Sever) // Sel'skoe hozyajstvo Rossii. - 1971. - № 9. - S. 31.
3. Denisov G.V. Ekologo-biologicheskie osnovy vozdelyvaniya mnogoletnih trav $\mathrm{v}$ zone vechnoj merzloty: avtoref. dis. ... d-ra biol. nauk / Centr. sib. botan. sad, Sib. otd-nie. Novosibirsk, 1987. - $32 \mathrm{~s}$.

4. Denisov G.V., Strel'cova V.S. Ekologiya i evolyuciya seyanyh lugov v kriolitozone. - Novosibirsk: Izd-vo RAN, 2005. - $240 \mathrm{~s}$.

5. Elovskaya L.G. Pochvy zemledel'cheskih rajonov Yakutii i puti povysheniya in plodorodiya. - Yakutsk, 1964. - $76 \mathrm{~s}$.

6. Pavlov N.E. Semenovodstvo i sortovedenie mnogoletnih trav $\mathrm{v}$ Yakutii. - Yakutsk: Tujmaada, 2012. - $111 \mathrm{~s}$. 